\title{
Consequências de duas definições de la langue no Curso de Linguística Geral de Ferdinand de Saussure*
} Some consequences of the two distinct definitions of la langue in Saussure's Cours de Linguistique Général

\section{Maria Francisca Lier-DeVitto}

(Pontifícia Universidade Católica de São Paulo - Faculdade de Filosofia Comunicação Letras e Artes/Departamento de Linguística/Programa de Estudos Pós-Graduados em Linguística Aplicada e Estudos da Linguagem/Divisão de Educação e Reabilitação dos Distúrbios da Comunicação - São Paulo - São Paulo - Brasil)

\section{ABSTRACT}

This article takes into account the astonishing verification that the fundamental concept, introduced by "the father of Linguistics", was fruitless within the field it appeared and was elaborated. Saussure is mentioned as the organizer of ideas about language, as the formulator of famous dichotomies, but the idea of la langue as the "object of Linguistics" and its possible consequences were not the focus of interest. Exceptions were, no doubt, Benveniste and Jakobson. On the whole, la langue, as "symbolic functioning", neither reducible to any particular language nor with grammar, did not guide the approach to Saussure. It should be pointed out that Saussure's destiny was quite different outside de field of Linguistics: Lévi-Strauss and Lacan are glaring examples of the impact of Saussure's ideas in Anthropology and in Psychoanalysis. Two conflicting definitions of la langue can be found in the Cours de Linguistique Générale.

* Este artigo é versão ampliada e modificada de artigo publicado em livro, pela EDUFU, em 2016. 
This article puts forth and explores the argument that one of them is at the bases of the devitalizing reading, mentioned above, and the other, that one which sustains the negative reasoning which relates la langue to the notion of "value", is responsible for the fructiferous effects of that concept in other realms.

Key-words: the object of Linguistics; two definitions of la langue; Saussure and Linguistics, Saussure and the Human Sciences.

\section{RESUMO}

Este artigo nasce da constatação de que o pensamento do "pai da Linguística” não rendeu no campo dos estudos linguísticos. Saussure é mencionado como organizador de ideias sobre a linguagem, como quem formulou famosas dicotomias, mas a novidade saussuriana, representada por la langue - o objeto perene e universal da linguagem - não teve incidência na produção linguística depois de Benveniste e Jakobson. Este não foi o destino de Saussure em outras ciências humanas. Levi Strauss e Lacan são exemplos maiores do impacto de Saussure fora de seu campo próprio. Há, no Curso de Linguística Geral, duas definições de língua, de certo modo conflitantes. Desenvolve-se, aqui, o argumento de que uma delas está na base da leitura desvitalizante de Saussure e outra, aquela que introduz o pensamento do negativo, vem como solo da produtividade que pode ter em outros campos.

Palavras-chave: objeto da linguística; duas definições de la langue, Saussure na Linguística, Saussure nas Ciências Humanas.

\section{Introdução}

Na medida em que reflita autenticamente o pensamento de Saussure, o Curso já não poderá se considerado como a fundação da Semiologia, mas, se muito, como o seu questionamento radical: significa dizer que ela não contém seu exórdio, mas, de certa forma, o seu encerramento. (AGAMBEN, [1993] 2007:242).

[Saussure] é "um clássico" a que sempre se faz referência, mas que não se lê. (RODRIGUES, 1980:40) 
Saussure é inegavelmente um clássico ${ }^{1}$. Nos termos de Foucault, ele seria um daqueles homens com o poder criador de "instaurar uma tradição... dentro da qual outros autores podem se colocar" (FOUCAULT, [1983]2002:57). Saussure perfaz a condição de autoria na medida em que seu pensamento criou "a possibilidade e a regra" de afetação e construção de outros textos. Pode-se reconhecer que a novidade saussuriana promoveu aberturas teóricas e descritivas inusitadas e heterogêneas na Linguística; aberturas, essas, que ressoam de forma produtiva e de modos particulares nas obras de Benveniste, Jakobson e Hjelmslev. O vigor/rigor da racionalidade saussuriana sobre a linguagem ultrapassou, de forma notável, as fronteiras da Linguística e afetou diferentes campos das ciências humanas ${ }^{2}$. A produção estruturalista, principalmente na Europa, atesta a força do "corte saussuriano" (PÊCHEUX, 1969:63, tradução minha). Dosse diz, a esse respeito, que: "O estruturalismo não é um método novo: é a consciência desperta e inquieta do saber moderno" (DOSSE, 1992: 222) (ênfase minha).

De fato, Saussure não introduz "um método": ele suspende métodos e descrições gramaticais (LEMOS et alli, 2003:173 tradução minha) - ele introduz uma nova racionalidade, que se faz notar em suas concepções inusitadas de linguagem e de unidade linguística; na enunciação de um "objeto concreto e integral" (SAUSSURE, [1916]1969:15) da Linguística; na sustentação da supremacia das operações do sistema sobre seus elementos, na instituição do "significante linguístico" e, ainda e acima de tudo, na implicação da noção de valor na reflexão sobre a linguagem, que suspende a ideia sedimentada de que a linguagem "é uma lista de termos que corresponderiam a outras tantas coisas" (SAUSSURE, [1916]1969:79). Foi, sem dúvida, esse conjunto de originalidades articuladoras que "abriu espaço para outra cois a diferente" sem deixar, no entanto, "de pertencer ao que a fundou" (FOUCAULT [1983]2002:60).

1. Maria Aparecida dos Santos (2015) discute, em sua tese: Autoria: as injunções do jogo significante, questões ligadas à autoria, desde uma perspectiva que implica o pensamento de Saussure.

2. Ver, a esse respeito, Dosse, F. (1991): A História do estruturalismo I e II. 
Lacan, em O Seminário: Livro XI, muito depois de 1956, qualificado como sendo o ano do início de seu ensino ${ }^{3}$, dirigindo-se às pessoas que, em 1964, iniciavam suas participações nos Seminários, critica o desprezo dos analistas pela fala (o único instrumento que sustenta a práxis do analista), sublinhado ter sido preciso revalorizá-la "para lhe devolver dignidade". Para isso, ele recorreu à Linguística, "cujo modelo é o jogo combinatório operando em sua espontaneidade, sozinho, de maneira pré-subjetiva - [sendo esta] a estrutura que dá seu estatuto ao inconsciente" (LACAN [1964]1973:25-26) (ênfase minha), em passo e compasso com Lévi-Strauss (1962) que pode, a partir de tal modelo de ciência, "explorar, estruturar, elaborar" o campo que ele "rotulou com o nome de Pensamento selvagem" (idem, ibidem, p. 25). Este preâmbulo nos coloca frente à verdade de que fundadores de discursividade não estão sujeitos ao desgaste do tempo - eles são, digamos, "imortais", fontes permanentes promotoras de caminhos e de novas direções argumentativas.

Tal afirmação não nos exime, mas exige, contudo, de interrogar sobre o modo de presença de Saussure na Linguística, principalmente quando se tem em conta uma pontuação contundente de Neidson Rodrigues feita em 1980 por ocasião do centenário da comemoração do nascimento de Saussure, na Faculdade de Filosofia da Universidade Federal de Minas Gerais. Rodrigues registra a surpresa que o levou a ler, estudar, o Curso de Linguística Geral. Ele escreve:

as citações sobre Saussure se multiplicavam (...). Mas, curioso: Saussure manifestava-se, desde o início, como origem, mas... origem repudiada. Todos o citavam, não para assumi-lo, mas... para negá-lo. É origem, mas sua obra, importante como começo, recebia atestado de passado.

\section{O filósofo continua:}

Apesar de referências e advertências (...) sobre a impoetância da obra de Saussure, e mesmo da afirmação de que o « Curso levanta uma série intérmita de problemas ${ }^{4}$, parecia-nos ver, em tais afirmações, apenas uma espécie de elogio fúnebre » (RODRIGUES, 1980:41) (ênfases minhas).

3. Miller ([1984]1987) situa este momento como aquele que corresponde ao do início da teorização sobre o Simbólico e da aproximação à Linguística.

4. Ver prefácio de Isaac Nicolau Salum à edição brasileira do Curso de Linguística Geral. 
Estas considerações de Rodigues compõem-se com outra, de Cláudia Lemos, proferida 15 anos depois, em 1995, desta vez em palestra na PUCSP, pela comemoração pelos 80 anos da morte de Saussure, promovida por psicanalistas:

Revisitar a obra de Saussure serve hoje, aqui, para comemorar, isto é, para juntos lembrarmos os oitenta anos de sua morte. Por si só este evento, o de comemorar uma morte, é significativo (.....). Não é, com efeito, a Linguística que a comemora, mas a Psicanálise, representada aqui pelo Núcleo de Psicanálise do Departamento de Psicologia Clínica da PUCSP. Isso já diz do destino de uma obra, da vida e da morte que estão para além do tempo da vida e da morte de um autor (LEMOS, 1995 :41) (ênfase minha).

Ambos os autores citados relacionam as menções a Saussure, na Linguística, a uma espécie de morte. Como entender essa situação? Somos instigados a refletir sobre a obscura atualidade de Saussure no campo da Liguística até os dias de hoje ${ }^{5}$.

No colóquio, Saussure no século $X X$, realizado em 2001 na França e na Suiça, abordamos (LEMOS et alli, 2003) a forma de recepção de sua obra, melhor dizendo, o tipo de leitura que se realizou e que se tem realizado no campo dos estudos linguísticos. Após extensa pesquisa bibliográfica, apontamos para a leitura empirista, desvitalizante e encobridora da novidade sassuriana:

Saussure não foi muito "além da sala de aula", lugar em que as antinomias se perpetuaram como "a novidade" acrescentada por Saussure à história do pensamento linguístico (...). Nos anos 80 e 90, Saussure deixa de estar presente inclusive nas "salas de aula", em que é simplesmente mencionado como o "pai da linguística moderna", sem que a natureza da contribuição que lhe rendeu esse "titulo" seja sequer examinada. (LEMOS, et alli,2003:173) (ênfase minha).

Fato inegável é que, quando se pronuncia o nome de Saussure nos meios acadêmicos, ele soa, com frequência, como "homenagem

5. Em 2013, no Brasil, foram realizados alguns eventos comemorativos dos 100 anos da morte de Saussure (em 22 de fevereiro de 1913). Em 2016, comemorou-se os 100 anos da publicação do Curso de Linguistica em evento realizado na UNICAMP, pelo GT ANPOLL: estudos suassurianos. Linguistas, independentemente da extensão do compromisso com o pensamento de Saussure, parecem admitir, portanto, que ele é « uma atualidade » 
póstuma" (RODRIGUES, 1980:41). Não se tem podido ultrapassa "a imobilidade instaurada com a redução de Saussure à nomeação de dicotomias" (LEMOS et alli, 2003:173 tradução minha). Desse modo, recolher efeitos da obra de Saussure, sua presença na Linguística não é tarefa muito fácil, embora não seja difícil concluir que a Linguística não chegou a tangenciar a novidade essencial presente no CLG. A leitura deste texto fundador foi guiada por um viés filológico, semiológico, que tendeu/tende a diluir o que ele contém de inusitado e revolucionário. Para sustentar este argumento, desenvolvo, neste artigo, um ponto que me parece decisivo na direção de leitura que se tem feito de Saussure; leitura, esta, que tem rendido poucos frutos na Linguística, embora outra tenha frutificado "do lado de fora": Lévi-Strauss, por exemplo, funda a Antropologia Estrutural e Lacan empreende seu "retorno a Freud".

\section{Sobre la langue}

Em Saussure, linguagem é a língua (la langue) e a fala (la parole). Convém assinalar, de imediato, que a língua, "parte determinada e essencial" da linguagem (SAUSSURE, [1916]1969:17), é de natureza teórica, intelectual: é "objeto posto", como assinalou Rodrigues (1980), não é da natureza de "objetos dados" (SAUSSURE, [1916]1969:15), empiricamente observáveis. Interessa esclarecer, também, que a língual la langue - objeto da Linguística - é "ao mesmo tempo integral ["um todo em si mesma"] e concreto" (idem, ibidem). Lembrando: Saussure pergunta no início do capítulo Objeto da Linguística: "Qual é o objeto ao mesmo tempo integral e concreto da Linguística". Trata-se, como disse, de um objeto que é da ordem de um concreto inteligível, apreensível em seus efeitos sensíveis e, portanto, diferente das abstrações gramaticais, definíveis por propriedades ${ }^{6}$. A fala, a face empírica, maté-

6. A questão da relação concreto-abstrato merece reflexão verticalizada, que não cabe abordar neste artigo. Sucintamente, "concreto", em grego, significa "com-tudo", "inteiro", "completo". Saussure, ao que tudo indica, está distante da ideia aristotélica de que apenas a substância seria concreta por ser ela composta de substrato ou matéria. Tal concepção de concreto liga-se à de entidades como algo tangível, no sentido de passível de ser experimentável pela sensação. Desses dois pontos de vista, somente as propriedades sensiveis poderiam ser da ordem dos "concretos". La parole, face empírica e sensível da linguagem, enquadra-se nesse sentido de concreto. La langue, contudo, é concreta num 
ria da Linguística, tem, diversamente, a natureza do concreto sensível, apreensível pela sensação ${ }^{7}$.

A língua é o objeto da Linguística. Para Saussure: "o estudo da linguagem comporta, portanto, duas partes: uma essencial, que tem por objeto a língua..." (SAUSSURE, [1916]1969:27). Esta tese positiva comporta a tese negativa, qual seja de que a linguagem não é o objeto da linguística (MILNER [2002]2003:23), cujo argumento é que "o conjunto global da linguagem é incognoscível..." (SAUSSURE, [1916]1969:28), a linguagem, diz ele, é "multiforme e heteróclita, o cavaleiro de muitos domínios (...) não se sabe como inferir sua unidade" (SAUSSURE [1916]1969:17). Dele decorre que a linguagem não poderia ser erigida como objeto "integral", "universal", de uma disciplina. Frente a uma espécie de quebra-cabeças conceitual, estabelecido pela complexa relação, postulada por Saussure, entre os termos linguagem, a língua, língua(s), fala - é preciso caminhar com cautela e rigor para que se venha a recolher consequências efetivas ${ }^{8}$.

Um passo decisivo nesta direção corresponde, a meu ver, ao reconhecimento da dificuldade que a obra de Saussure coloca e de complexidades que a novidade introduzida envolve, entre elas, a de distinguir $a$ língua (la langue) de uma língua. O objeto teórico é um funcionamento, que não comporta por princípio, singular ou plural. Uma língua/línguas, pertence ao domínio do sensível/audível, do concreto-sensível, como disse acima e ficam, então, do lado de la parole: língua/línguas podem ser contadas, classificadas e, portanto, alojadas no espaço da "matéria"

pode ser "concreta" quando trata de desenvolvimento dialético. Resumidamente, a questão do concreto hegeliano liga-se ao processo dialético e articula-se à noção do "universal concreto": a única coisa "plenamente real". Trata-se, aqui, do universal que pode realizar-se concretamente e de modos muito diversos. La langue parece enquadrar-se no perfil desse universal-concreto, que guarda algo do "realismo da abstração" de Platão, para quem ideias não são "diminuições" da realidade. Nesse caso, o "abstrato" enquanto "universal" é mais real do que o particular. Tal proximidade com a ideia de "concreto" em Platão, contudo, não é autorização para que se diga que la langue seja inata.

7. Assim, "fala" é matéria sensível que, como tal, ultrapassa a esfera do enunciado. Ela

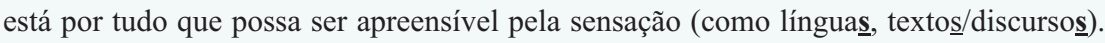
La langue, por sua vez, não comporta singular ou plural, já que é signo de estrutura: tem funcionamento "perene e universal" (SAUSSURE, [1916]1969 RESUMO

8. Ver "Le «saussurisme» en Amérique Latine au XXe siècle" (LEMOS, et alli 2003) e, também, de Lier-DeVitto (2015). 
da Linguística, i.e., no espaço de "todas as manifestação da linguagem humana" (SAUSSURE [1916]1969:13).

Sem este cuidado primeiro, o sentido profundo da revolução saussuriana fica sob o risco de permanecer encoberto no campo dos estudos linguísticos ${ }^{9}$. Enfim, la langue não equivale à língua/línguas e nem fala pode ser reduzida a "ato individual de vontade e inteligência", de que o falante é senhor (SAUSSURE, [1916]1969:22). Fato é que "o percurso de Saussure na teorização sobre la langue - a língua - aponta para uma preocupação a respeito da fala" (SILVEIRA, 2013:55). Uma preocupação que fica como tensão latente em sua obra. Saussure morreu, lembra Silveira, antes de ministrar o seu último curso na Universidade de Genebra que teria como título, precisamente, Linguística da Fala. Este "curso não iniciado nos lega um conceito por se fazer" (SILVEIRA, 2013:52). Não convém, portanto, simplificar o problema.

As considerações acima indicam ser preciso "ir e vir" no Curso, nos Escritos e nos manuscritos para apreender, na literalidade do texto e nas entrelinhas, como diz Rodrigues, o Saussure inovador, revolucionário, e não um simples organizador de noções linguísticas e fundador de dicotomias. Contra a simplificação do pensamento de Saussure, somos convocados a "acordar de nosso sonho infantil" (RODRIGUES, 1980:18); a abrir mão de uma posição de leitura que nos leva a encontrar no texto um já-sabido. Sim, leituras filológicas/semiológicas e/ou gramatical foram/são responsáveis pelo encobrimento da novidade que o Curso porta; leituras que deixaram em seu rastro o peso da "origem repudiada" e do "elogio fúnebre" (RODRIGUES, 1980:17).

As dualidades são, a rigor, nada representativas da verdadeira "novidade saussuriana" - elas preparam a introdução da novidade, de la langue como o objeto integral da Linguística. As dicotomias, no Curso de Linguística Geral (CLG), são apresentadas como argumentos em favor das limitações de pontos-de-vista parciais, ainda que impliquem a complexidade de objetos com duas faces solidárias e iredutiveis: ,“...

9. Na Filosofia e nas Ciências Humanas, Saussure rendeu redirecionamentos teóricos fundamentais - nesses lugares, a noção de significante e a radical mudança de raciocínio (de indutivo para dedutivo) produziram alterações radicais (Koyré [1943]1991; Fachini, (2013). 
o fenômeno linguístico apresenta perpetuamente duas faces que se correspondem e das quais uma não vale senão pela outra e, mais:

(...) qualquer que seja o lado por que se aborda a questão, em nenhuma parte se nos oferece integral o objeto da Linguística (...). Há, segundo nos parece, uma solução para todas essas dificuldades: é necessário colocar-se no terreno da língua e toma-la como norma de todas as outras manifestações da linguagem. De fato, entre tantas dualidades, somente a língua parece suscetivel duma definição autônoma e fornece um ponto de apoio satisfatório para o espirito. (SAUSSURE, [1916]1980:16 -17) (ênfases minhas).

A língua é o objeto integral e a solução saussuriana para as dificuldades colocadas pelas abordagens tradicionais da linguagem (gramatical e filológica), que a fragmentam em estratos plurais (fonético, fonológico, morfológico, sintático, semântico e assim por diante). Ao contrário disso, propõe Saussure, "a língua é um todo em si mesma e um princípio de organização" (SAUSSURE, [1916]1969:16-7). Em outros termos: "é $a$ língua que faz a unidade da linguagem" (SAUSSURE, [1916]1969:18) - ela é passível de ser "o objeto" de uma área de saber, que, de um ponto de vista lógico, não poderia ser parcial e diversificado. Esse objeto integral/teórico abrange toda a diversidade empírica, toda a "assistematicidade" das manifestações da linguagem. Interessa reafirmar que la langue é um funcionamento governado por operações in praesentia e operações in absentia, que articulam as leis de referência interna do sistema.

Tendo assentado este ponto de partida, introduzo o problema, indicando a constatação incômoda de que há, no Curso de Linguística Geral, duas definições de língua, em grande medida, conflitantes. Elas produzem, a meu ver, consequências decisivas: os dois vértices de trabalhos que se desenvolveram/desenvolvem a partir de leituras do texto fundador - são dois caminhos diferentes e divergentes. Na página 24, do Curso de Linguística Geral lê-se:

A língua é um sistema de signos que exprimem ideias (SAUSSURE, [1916]1969:24).

Esta definição aparece num parágrafo que precede aquele em que Saussure sugere a instituição de "uma ciência que estude a vida dos 
signos no seio da vida social" a Semiologia, que, diz ele, deveria ensinar "em que consistem os signos, que leis os regem" (SAUSSURE, [1916] 1969:24). Saussure acrescenta a isso que, para abordar adequadamente o problema semiológico, é preciso "formulá-lo convenientemente", ou seja, discuti-lo na referência à "língua em si" (SAUSSURE, [1916] 1969:24)Dito de outro modo, mesmo neste enquadre saussuriano, um linguista não estaria autorizado a estudar o signo desligado do sistema, como "unidade em si".

Historicamente, teorias de linguagem e teorias do signo eram trabalhadas separadamente. As teorias gregas de linguagem não recorrem ao signo; a noção de signo se desenvolve por si mesma, sem referência especial à linguagem. Nos estoicos, "signo" designa, fundamentalmente, uma forma de racionamento: do perceptível, deduzir um imperceptível. (MILNER, [2002]2003:28)

\section{O signo linguístico}

Conceber o signo como forma de racionamento situa (de forma implícita) a linguagem na mesma lógica. Daí resulta que ela fica encapsulada na ideia de que é nomenclatura: manifestação sensível do pensamento que é, em si, imperceptível. Mas Saussure vem depois de Port Royal, quando falar de linguagem envolvia falar de signo, ele "fez algo completamente diferente" (MILNER, [2002]2003: 29); seu modelo afasta a tradição da assimetria, da heterogeneidade (entre perceptível e imperceptível) - corte radical que parece ter escapado a muitos leitores do Curso. Contudo, é preciso reconhecer a complicação que decorre da definição de "língua como sistema de signos que exprimem ideias" propicia tal leitura.

O problema reside também na concepção de que signos são elementos internos ao sistema enquanto unidades prévias, estabelecidas sem o concurso de suas operações próprias. De fato, nesta primeira definição de língua, há possibilidade de os signos serem considerados isoladamente, apesar do assinalamento de Saussure, mencionado acima, sobre a necessária referência ao sistema. Lê-se no CLG que: "há uma faculdade de associação e de coordenação que se manifesta desde que não se trate mais de signos isolados" (SAUSSURE [1916]1969:21) uma oscilação? Seria possível considerá-los isoladamente? Seria 
possível entender que as operações de la langue incidiriam sobre elementos dados. Coloca-se aí, portanto, um problema lógico, que remete à questão da positividade do signo e do dilema de sua determinação. Problema que Saussure procura enfrentar num longo percurso que corresponde à primeira e à segunda parte do CLG. Este percurso encaminha o raciocínio de dissolução da primeira definição e da elaboração da segunda

A definição de língua como "sistema de signos" pode levar (e tem levado) ao entendimento de que o sistema é conjunto composto por elementos prévios sobre os quais incidem suas operações para produzir relações de sentido. Nesse ambiente, não se dissolve, de forma incisiva, as ideias de referência, nem de representação, que parasitam as noções de signo e de língua (como "nomenclatura", diria Saussure). Parece-me que este assinalamento é relevante para nos aproximarmos do "corte saussuriano", que envolve a diluição de todo e qualquer resíduo de substância do signo.

Saussure "fez algo completamente diferente", assinalou: o signo saussuriano apoia-se na simetria e na reciprocidade; ele não é uma realidade que representa outra realidade (como no caso de relações assimétricas). De fato, Saussure fala em associação e em associação recíproca - é assim que as flechas invertidas que escrevem o signo devem ser lidas (SAUSSURE, [1916]1969:80); nunca como relação de representação: "a relação do signo com a coisa significada não importa absolutamente a Saussure", sublinha Milner ([2000] 2003:30). Além disso, completa ele, "Saussure se serve da palavra signo com certa repulsa" (MILNER [2002]2003:31), impregnada que tal noção é da reflexão filosófica. Podemos, de fato, considerar que, para Saussure, o signo linguístico "não é o objeto da teoria, mas o meio de expor uma teoria, cujo objeto é completamente outro" (MILNER, [1978]2012:57) (ênfase minha). Ele é o "meio", o caminho da construção do signo linguístico, ou melhor, da desconstrução do signo filosófico, que implica e sustenta a noção de representação. Desconstrução, esta, que segue na direção de sua dissolução pari passu com a implicação da noção de valor, cuja lógica exige interrogar a relação entre significante e significado - é o que ocorre quando Saussure afirmar que o signo é "radicalmente arbitrário" (VILAR e CARVALHO, 2014). Esta solução abala a ideia de "unidade complexa", que é avançada no início do CLG. 
A arbitrariedade radical dilui, de fato, a "associação necessária" entre significante e significado ${ }^{10}$. Entende-se, assim, que Milner afirme que "a palavra arbitrário resume, justamente, a ausência de toda relação" (MILNER [2002]2003:35).

Saussure afirma: "a ideia de valor (...) nos mostra que é uma grande ilusão considerar um termo simplesmente como a união de certo som com certo conceito" (SAUSSURE [1916]1969:132) (ênfase minha). A modificação radical do signo - que corresponde ao abalo na ideia de "associação" - acomodada na definição de "língua enquanto sistema de signos" - obriga interpretar a "barra" como "barreira", como resistência à união entre significante e significado i.e., como "impossibilidade do signo de produzir-se na plenitude da presença"; produzir-se como positividade (AGAMBEN, 2007:246).

Esta profunda modificação no estatuto do signo em relação ao jogo do sistema é solidária à postulação da segunda definição de la langue no Curso de Linguística Geral, qual seja:

A língua é um sistema de valores puros (SAUSSURE [1916]1969:130).

Decorrência direta e lógica desta definição de la langue é a de que signos são efeitos das relações do sistema e não elementos (prévios) em relação ao sistema, que possam ser considerados isoladamente. Fica claro, portanto, que o la langue é mobilidade simbólica e que o signo é valor que se estabelece, ganha consistência provisória, no "só depois" das operações do sistema. Elimina-se, desse modo, qualquer suspeita sobre sua positividade. Na teoria do valor, Saussure libera o signo de qualquer motivação ligada à substância conceitual ou fônica.

Sendo assim, não se está autorizado, nos termos saussurianos, a abordar a problemática do signo desligada das operações do sistema, como se o signo pudesse ser tratado como "unidade em si". Tal exigência não parece ter sido acolhida por linguistas, como insisto neste artigo. A complicação que decorre da definição de "língua como sistema de

10. Não se pode ignorar aqui a brilhante discussão de Benveniste sobre o "arbitrário do signo". Embora de grande relevância e destaque, este artigo não abala a força da construção-dissolução da signo por Saussure, construção que permitiu Lacan recolher e retirar de Saussure a primazia do "significante". 
signos que exprimem ideias" é que ela propicia a leitura de que os signos, como elementos internos ao sistema, sejam unidades já prontas, estabelecidas sem o concurso das operações do sistema, i.e., dos eixos sintagmático e associativo, que incidiriam sobre elementos dados para produzir relações de sentido. Nesse ambiente, não se pode vislumbrar a radical diferença que há entre signo filosófico e signo linguístico, nem se faz valer a força das leis de referência internas ao sistema.

\section{Considerações finais}

Resumidamente, a primeira concepção do objeto da Linguística joga luz sobre "a experiência de impasse", como diz Agamben a respeito de Saussure, um homem que buscou eliminar todo e qualquer resíduo de positividade do coração da linguagem. A primeira definição introduz, contudo, o signo como problema por conter o dilema de sua determinação Saussure desata este nó ao elaborar a segunda definição: A língua é um sistema de valores puros. Deveria bastar, entretanto, a palavra de Saussure no Curso: "a ideia de valor (...) nos mostra que é uma grande ilusão considerar um termo simplesmente como a união de certo som com certo conceito". A leitura de Agamben é cortande: a barra entre significante é "traço de resistência à união entre significante e significado" (AGAMBEN, [1993] 2007:246) . Não foi outra a interpretação de Lacan. Com a segunda definição de língua como um sistema de valores puros e do entendimento do signo linguístico como efeito das relações do sistema, penetramos no domínio da negatividade em que o sistema é mobilidade simbólica e o signo é valor flutuante, definido no "só depois" das operações do sistema. Saussure libera o signo de qualquer motivação ligada à substância conceitual ou fônica: "valores [são] inteiramente negativos e relativos: o vínculo entre a ideia e o som é radicalmente arbitrário", (SAUSSURE [1916]1969:132), conclui Saussure ([1916]1969:132), no Curso de Linguística Geral.

Uma leitura pela via do negativo permite considerar que o projeto semiológico foi sugerido, mas abortado pelo próprio Saussure. Essa é a conclusão de Agamben ([1993] 2007:242) que está como epígrafe deste texto. Para ele, o Curso de Linguística Geral "não contém seu exórdio, mas, de certa forma, o seu encerramento". Pode-se, porém, que a noção de signo continua, na Linguística, presa uma "redução 
metafísica do significar", ou seja, ao signo como relação positiva dentre imagem acústica e conceito, independente do sistema (do objeto da linguística). Enfim, a Linguística fixou-se na definição de que "a língua é um sistema de signos que expressam ideias". Nela, portanto, floresceu uma direção que encobriu a novidade da introdução de um pensamento sobre a linguagem como domínio de diferenças eternamente negativas. Nesse sentido é que Saussure representa "um corte" em relação a todo pensamento linguístico e à tradição metafísica que o precederam. Saussure instala um novo saber, uma nova discursividade: ele é UM e não "mais um" na história das ideias linguísticas (LIERDeVITTO, 2013:114). Em territórios exteriores, de que a Antropologia e Psicanálise lacaniana são exemplos maiores e não únicos, foram expressivos e revolucionários os efeitos do pensamento da diferença e do negativo que está em Saussure. Dois caminhos diferentes e divergentes. Manter encoberta a novidade saussuriana a imobiliza, mas desvitaliza igualmente o campo em que ela apareceu. A força de seu movimento transparece, contudo, em campos vizinhos.

Recebido em: 27/12/2016 Aprovado em: 17/05/2017

E-mail: flier@pucsp.br

\section{Referências}

Agamben, Giorgio. [1993]2007. Estâncias: a palavra e o fantasma na cultura ocidental. Belo Horizonte: Editora da UFMG.

ANDRADE, Lourdes. 2003. Sobre 'ouvir'e 'escutar' na constituição da clínica de linguagem. Tese de doutorado inédita. PPG em LAELPUCSP.

Dosse, François. [1991]1983. A História do estruturalismo I: o campo do signo 1445/1966. Campinas: Editora da Unicamp \& Editora Ensaio movimento de ideias/ideias em movimento.

FACHINI, Sonia Regina Victorini. 2013. A posição do investigador: reflexões sobre ética, método e análise. Tese de doutorado inédita. PPG em LAEL-PUCSP.

Foucault, Michel. [1983]2009. O que é um autor? In: Barros DA MotтA, Manoel (org). Ditos \& Escritos III. Rio de Janeiro: Forense Universitária.

Koyré, Alexandre. [1943]1991. Estudos de história do pensamento cientifico. São Paulo: Editora Forense Ltda. 
LACAN, Jacques, [1964] 1973. O Seminário: livro 11 - Os quatro conceitos fundamentais da Psicanálise. Rio de Janeiro: Jorge Zahar Editor.

Lemos, Claudia Thereza. 1995. Da morte de Saussure o que se comemora? Psicanálise e Universidade, 3: 41-51.

Lemos, Cláudia Thereza Guimarães; Lier-DeVitto, Maria Francisca; ANDRAdE, Lourdes; SilveIRA, Eliana Mara. 2003. Le «saussurisme» en Amérique Latine au XXe siècle. Cahiers Ferdinand de Saussurerevue suisse de linguistique générale, 56:165-176 Genève, Librairie Droz, S.A.

LÉvi-Strauss, Claude. 1962. Pensamento Selvagem. Paris: Editora Plon.

Lier-DeVitto, Maria Francisca de Andrade Ferreira. 2013. Efeitos do pensamento de Saussure na teorização sobre erros e sintomas na fala. In: Fiorim, José; Flores, Valdir; BARBisan, Leci (orgs.). Saussure, a invenção da linguística. São Paulo: Editora Contexto.

Lier-DeVitto, Maria Francisca. 2016. Sobre o que se colhe e o que se recolhe na leitura de Saussure. In: Cristianini, A.C. e Resende OtтоNi, M.A. (orgs.). Estudos linguísticos: teoria, prática e ensino. Uberlândia: EDUFU.

MiLLER, Jacques Allain. [1984]1987. Percurso de Lacan: uma introdução. Rio de Janeiro: Campo freudiano no Brasil e Jorge Zahar Editor.

MiLner, Jean-Claude. [1978] 2012. O amor da língua. Campinas: Editora da Unicamp.

1987. Introduction à une science du langage. Paris: Éditions de Seuil.

[2002]2003. El periplo estructural: figuras y paradigma. Buenos Aires: Amorrortu Editores.

PêCheux, M. 1969. Les sciences humaines et le 'moment actuel'". Paris: La Pensée, n. 143:62-79.

Rodrigues, Neidson. 1980. Introdução ao pensamento de Saussure. Série - Ciência e Linguagem. Rio de Janeiro: Achiamé.

SAntos, Maria Aparecida. 2015. Autoria: as injunções do jogo significante. Tese de doutorado, LAEL-PUC-SP.

Saussure, Ferdinand de. [1916]1969. Curso de linguística geral. São Paulo: Cultrix.

Silveira, Eliane Mara. 2007. As marcas do movimento de Saussure na fundação da linguística. Campinas: Mercado de Letras/Fapesp. 2018. O lugar do conceito de fala na produção de Saussure. In: Fiorim, José; Flores, Valdir; BarbisAn, Leci (orgs.). Saussure, a invenção da linguística. São Paulo: Editora Contexto.

VILAR, Maria de Fátima \& CARVAlHo, Glória Maria Monteiro. 2014. Pontos polêmicos na concepção saussuriana de signo. Matraga, 21, n. 34: 168-179. 
34.3

2018

Ana Carolina Vilela-Ardenghi \& Ana Raquel Motta 